\title{
Clinical and Computed Tomographic (Cbet) Evaluation of Portland Cement Pulpotomy in Primary Molar: A Case Report
}

\author{
Kamrun Nahar ${ }^{1}$, A.K.M.Bashar ${ }^{2}$, Mozammal Hossain ${ }^{3}$, Ali Asgor Moral' \\ ${ }^{1}$ FCPS part II trainee, ${ }^{2}$ Associate Professor, ${ }^{3}$ Assistant Professor, ${ }^{4}$ Dean, Faculty of Dentistry \& Professor Department of Conservative Dentistry and \\ Endodontics, BSMMU, Dhaka
}

\begin{abstract}
:
The present case describes the clinical \& radiographic outcome of a Portland Cement pulpotomy. The 5 years old girl presenting extensive carious exposure in her mandibular left 2nd deciduous molar and was suffering pain in her left lower jaw only on exposure to cold for last 2 days. She was ultimately diagnosed clinic-radio-graphically as a case of irresersible pulpitis. Coronal pulpotomy procedure was carried out in the responsible tooth and Portland cement (PC) was applied as a medicament after pulpotomy. At the $3 \&$ 6-months follow-up appointments, treated tooth was asymptomatic clinically and radiographic examinations revealed no sign of periradicular pathosis in the pulpotomized teeth. Additionally, the formation of a dentin bridge immediately below the PC in the treated tooth was confirmed by RVG and CBCT.
\end{abstract}

Key words: Mineral Trioxide Aggregate, Portland cement, Primary teeth, Pulpotomy.

[BSMMU J $2014 ; 7$ (2) : 141-146]

\section{Introduction:}

Pulpotomy is the most widely accepted clinical procedure for treating primary teeth with inflammation of the coronal pulp caused by caries with no involvement of the radicular pulp. This technique consists of removal of the coronal pulp and placement of a medicament over the amputated radicular pulp for its healing. The purpose is to remove the bacterial infection leaving the treated tooth asymptomatic until its exfoliation ${ }^{1-2}$.

Medicaments applied to radicular pulp tissue after pulpotomy have included formocresol ${ }^{3}$, ferric sulphate ${ }^{1}$, calcium hydroxide ${ }^{1}$, and mineral trioxide aggregate (MTA) ${ }^{4,5}$. MTA is considered as the most effective medicament after pulpotomy in human primary teeth. The Important barriers to the widespread use of MTA in pediatric dentistry as pulpotomy medicaments include its perceived cost, difficulties with storage and appropriate training. Recently, great interest has been focused on the

Address for Correspondence: Dr. A.K.M. Bashar Associate Professor Department of Conservative Dentistry \& Endodontics, BSMMU.

Mobile: 01710884444 evolution of Portland cement (PC) as an effective and economic alternative to MTA, and several studies have compared both materials ${ }^{6-9}$.

PC is fine powder composed of $65 \%$ lime, $20 \%$ silica, $10 \%$ alumina and ferric oxide and 5\% other compounds, differs from MTA by the absence of bismuth ions $8^{-11}$ and the presence of potassium ions ${ }^{7}$. Both materials have comparable antibacterial activity ${ }^{8}$ and almost identical properties macroscopically, microscopically ${ }^{9,12}$ and by $\mathrm{X}$-ray diffraction analysis ${ }^{11}$.The main goals of using calcium hydroxide, MTA and Portland cement are to induce dentin bridge formation by pulp cells and to maintain pulp vitality ${ }^{13}$. It has also been shown that PC and MTA have similar effect on pulpal cells when used for direct pulp capping in rat teeth ${ }^{14}$. Holland et al. ${ }^{14}$ studied the rat subcutaneous connective tissue response to implanted dentin tubes filled with MTA, PC and calcium hydroxide and found very similar mechanisms of action. In addition, both MTA and PC allowed dentin bridge formation in pulpotomized tooth, performed in $\operatorname{dog} \mathrm{s}^{15}$. Finally, Min et al. ${ }^{16}$ observed that PC allowed the expression of mRNAs of a dentin-specific protein and a 
non-collagenous protein involved in mineralization in cultured human pulp cells.

Taking into account the low cost and widely availability with apparently similar properties of PC in comparison to MTA, ${ }^{7,17,18}$ it is reasonable to consider PC as an effective and economic substitute for MTA in endodontic applications. There are several reports on the use of PC as a medicament in human primary teeth. ${ }^{19-21}$ All this has resulted in a significant body of research that shows that $\mathrm{PC}$ appears to be an effective and economic substitute for MTA.

This paper presents a clinical case in which PC was applied as a medicament after pulpotomy of mandibular primary molar in a 5years child.

\section{Case report :}

A 5 years girl attended at the dept. of Conservative Dentistry \& Endodontics, BSMMU, with mild pain on her left lower jaw for last 2 days. She had been feeling pain only when she ate cold food and resolves within short period. On clinical examination, the mandibular left $2^{\text {nd }}$ deciduous molar had extensive carious exposure and was briefly exaggerated to cold that releved within 4-5 seconds after removal of the stimulus. The previously untreated tooth had no signs of radicular pulp degeneration, furcal involvement, internal or external pathological root resorption, or pathological thickening of the periodontal membrane (fig 1) as well as no clinically detectable increased mobility. A diagnosis of reversible pulpitis of mandibular left $2^{\text {nd }}$ deciduous molar due to caries was made. Since the patient had no systemic pathology or known allergies to the compounds from which PC is made Pulpotomy with Portland Cement (PC) of the tooth was the planed as treatment.

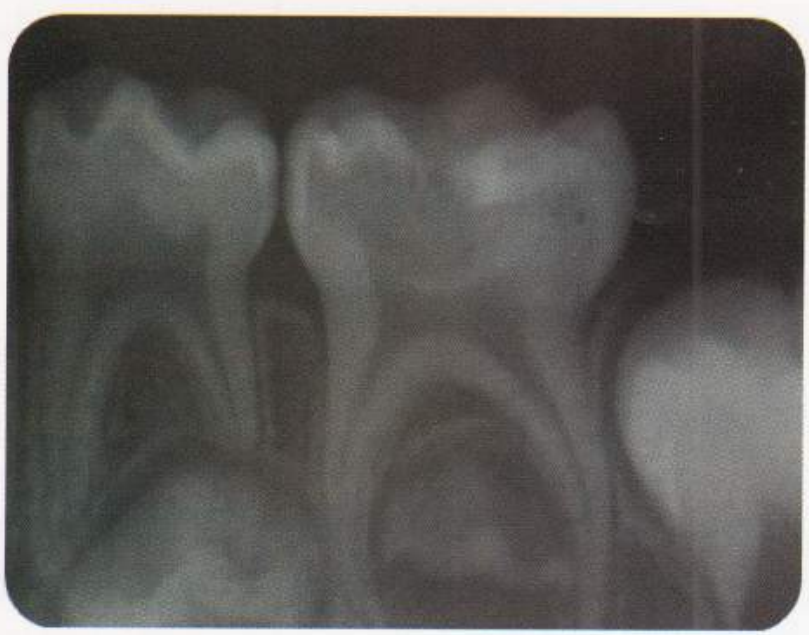

Fig 1: Preoperative X-ray showing Tooth no 65 having deep carious lesion extending upto pulp horn but no sign of periapical lesion.

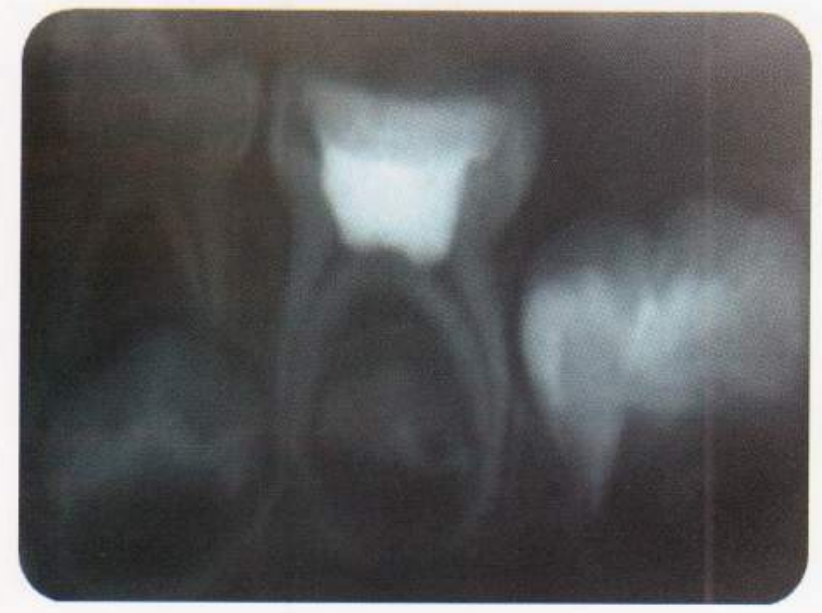

Fig 2: Immediate post operative X-ray, pulpotomy carried out, pulp chamber filled with radio-opaque Portland cement and restorative Glass Ionomer filling material

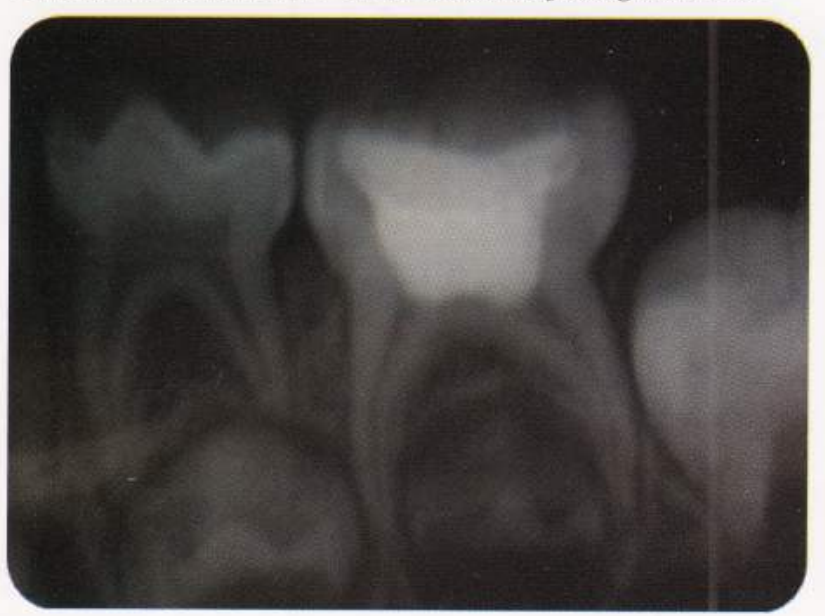

Fig 3: Three (3) months follow up X-ray, No evidence of periapical lesion, no sign of resorption. Initial formation of dentin bridge immediately below PC observed. 


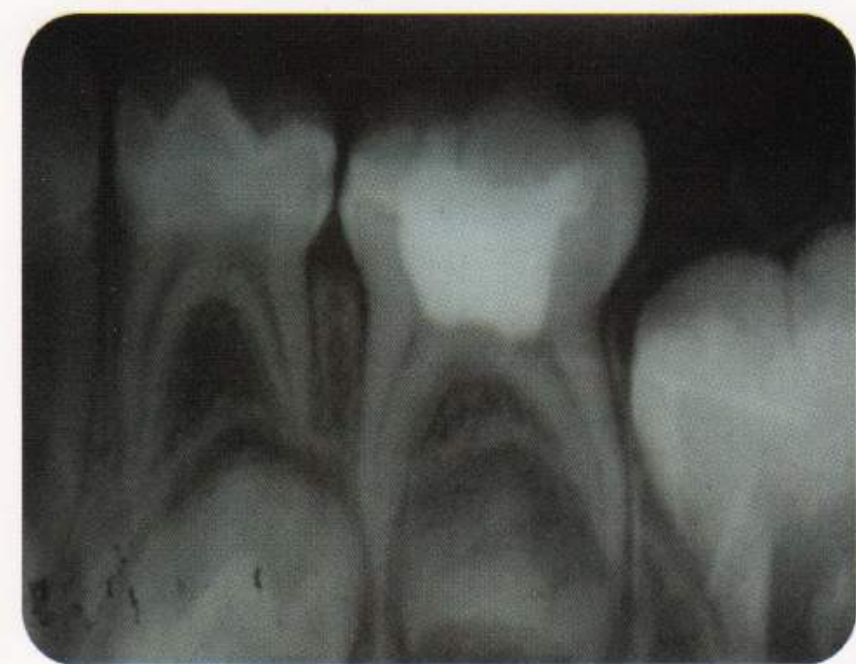

Fig 4: Six (6) months follow up X-ray, No evidence of periapical lesion, no sign of resorption, formation of a dentin bridge $(D B)$, immediately below the PC; especially in the mesial root of the treated tooth

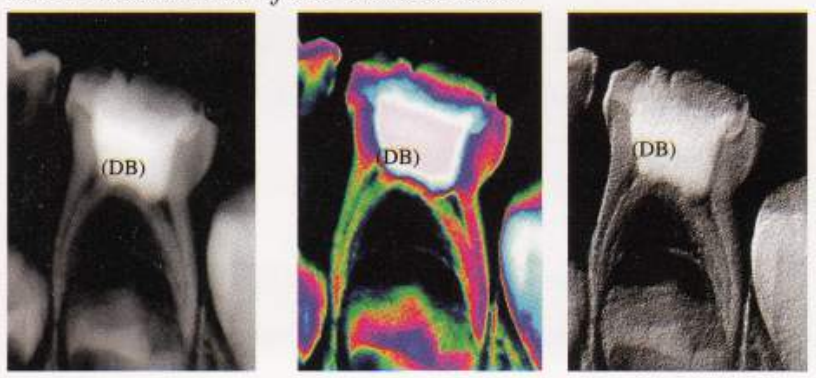

Fig 5: Six (6) months follow up radiograph by RadioViseo Graphy (RVG). All Gray scale view, multicolor view and $3 D$ view confirms formation of a dentin bridge $(D B)$, immediately below the PC; especially in the mesial root of the treated tooth.
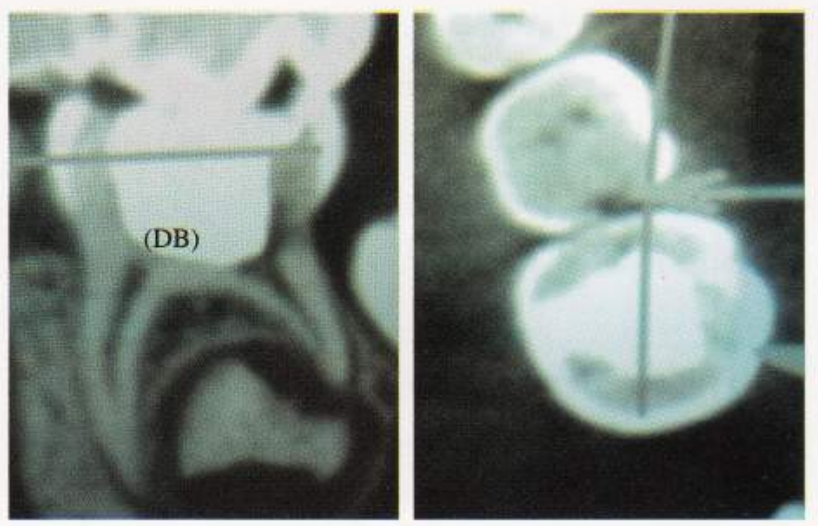

Fig 6: Six (6) months follow up radiograph by Cone Beam Computed Tomography (CBCT) confirms formation of a dentin bridge $(D B)$, immediately below the PC; especially in the mesial root of the treated tooth.
Treatment Procedure:

Disinfection of the operative field and proper sterilization of instruments was ensured. After profound anesthesia and proper Isolation of the teeth, surrounding caries was removed by using number- 4 new sterile round bur with a high speed hand piece using copious water spray. Then, the roof of the pulp chamber was removed with the same bur running with high-speed hand-piece.

Coronal pulp from pulp chamber was removed manually by using sterile excavator until the orifices of canal are seen. Finally, the pulp chamber was rinsed with normal saline and a small cotton pellet soaked with normal saline was pressed until bleeding was controlled.

Sterilized Portland Cement (PC) was mixed with Bismuth Oxide at a ratio of $4: 1$. PC was then mixed with sterile water using plastic spatula in a ratio $3: 1$. The smooth mix was applied over the amputed pulp and into the base of the prepared cavity using a cement lifter. Mixed cement was then condensed properly over the chamber by using a sterile cotton pellet moistened with distilled water. A moist cotton pellet was then placed over the PC and the rest of the cavity was filled with Zinc oxide eugenol cement to allow the PC to set initially. After 1hour, the cotton pellet was removed; initial setting of the Cement was confirmed by probing its surface. Fuji-IX Glassionomer cement was then placed over the rest of the cavity. Bite was checked for any high spot and 2 coats of Varnish were applied over the Glassionomer Filling. A Post operative radiograph was taken (fig 2 ). The patient was recalled on the next day for evaluation and the treated tooth found asymptomatic.

The periodic follow-up examinations were carried out $3 \&$ 6 months after the end of the treatment. Each check-up involved a clinical and radiographic examination of the pulpotomized teeth. Clinically, the tooth was asympto- 
matic and functioning. Radiographic examinations revealed formation of a dentin bridge, immediately below the PC; especially in the mesial root of the treated tooth (fig 3 \& 4). The dentin bridge was confirmed by RVG \& $\mathrm{CBCT}$ at 6 months follow-up period (fig $5 \& 6$ ).

\section{Discussion :}

Pulpotomy with Portland cement as medicament in the present case resulted in an uneventful post operative condition immediately and over a period of six months. There was no inflammation of the surrounding gingival tissue swelling, sinus tract or mobility and radiographically there was nothing suggestive of internal root resorption and furcation radiolucency. All these were determined as the criteria of success by Sakai et al ${ }^{19}$

The clinical and radiological findings of the present case also came out with similarity when observing the study carried out by Conti et al. ${ }^{22}$ The clinical and radiological evaluation of three primary molars after Portland cement pulpotomy by Conti et $\mathrm{al}^{22}$ reveals that these 3 teeth remained asymptomatic and vital with the formation of dentin bridge immediately below the PC.

However, present case differs with the study by Conti et $\mathrm{al}^{22}$ in respect of time needed for dentin bridge formation. Conti et $\mathrm{al}^{22}$ when comparing pulpotomy of 30 human primary molar with MTA \& PC, dentin bridge deposition was radiographically detected in all available teeth at 6 months after placement. In the present case a hard tissue barrier was observed immediately below the PC after 3-month follow-up, which was confirmed at the 6-month follow-up appointment. But faster pulp tissue reactions with an earlier formation of the mineralized barrier is supported by the study of Barbosa ${ }^{20}$ and Sampaio. ${ }^{21}$ Both of them found a faster pulp tissue reactions with an earlier formation of the mineralized barrier over the capped pulp when used PC as a pulp capping material. While it has been claimed that minimum time requirement for the induced hard tissue barrier formation is 6 week. ${ }^{23}$ The success of PC utilization may be explained by the strong initial stimulus, able to cause an immediate response of osteo-dentin formation in an attempt to isolate the remainders of the pulp from the action of the material. ${ }^{24}$

The beginning of mineralized deposition could be radiographically detected in $100 \%$ of the teeth treated with PC and $57.14 \%$ of the teeth treated with MTA ${ }^{25}$, whereas after MTA pulpotomy Soares ${ }^{25}$ reported $89.28 \%$, Hollad et al. ${ }^{14}$ and by Pitt Ford et $\mathrm{al}^{26}$ reported $100 \%$ complete tubular bridge \& $84.6 \%$ complete tubular dentin bridge formation was reported after PC-pulpotomy; Although The dentinal bridge formation in the present case was finally evaluated by CBCT but the type of the bridge could not observed histologically, as the patient was too younger for exfoliation of the tooth.

Portland cement in its natural state is slightly radio opaque but it fails to meet the ISO requirement for radiopacity. The lack of radiopacity in pure PC is due to the absence of bismuth, a chemically inert radiopacifier, in its composition $^{7}$. To overcome this disadvantage, and radiopacifier additions have been carried out in this case. Comparing different radiopacifier, bismuth oxide presented the highest radiopacity value than that of dentin \& may potentially be added to the Portland cement as radiopacifying agent ${ }^{27}$. The compressive strength of $\mathrm{PC}$ is not altered with $20 \%$ bismuth oxide, and the material continues to be biocompitable ${ }^{10}$.

A major concern regarding the use of water-based cements is the amount of leachable arsenic present in the material. Arsenic are impurities of limestone that is used in the manufacture of PC12. Duarte, et al. ${ }^{28}$ showed that the concentration of arsenic is in PC $(0.007 \mathrm{mg} / \mathrm{kg}$ body wt after $3 \mathrm{~h}$ and $0.006 \mathrm{mg} / \mathrm{kg}$ body wt after $168 \mathrm{~h}$.) is below the toxic level (140-210 mg/kg body wt) and 
below the toxic level (140-210 $\mathrm{mg} / \mathrm{kg}$ body wt) and closely similar to that present in MTA $(0.002 \mathrm{mg} / \mathrm{kg}$ body wt) . Moreover, the highest content does not necessarily indicate a great release demonstrate no contraindication of the use of that material in clinical practice concerning the presence of this chemical element. In my case, the patient was clinically assessed in every follow-up and no sign of arsenic poisoning was detected by this time.

\section{Conclusion :}

The Clinical and Radiographic evaluation of Portland cement pulpotomy result a successful outcome in the present case. Combining scientific information, human health and social value which are very encouraging. But before unlimited clinical use, further studies with large samples and long follow-up assessments are needed.

\section{References :}

1. Conti et el, Pulpotomies with Portland cement in human primary molars. J Appl Oral Sci. 2009; 17(1):66-9.

2. Fuks AB. Current concepts in vital primary pulp therapy. Eur J Pediatric Dent. 2002;3:115-20

3. 3.Agamy HA, Bakry NS, Mounir MMF, Avery DR. Comparison of mineral trioxide aggregate and formocresol as pulp-capping agents in pulpotomized primary teeth. Pediatric Dent.2004;26:302-9.

4. Estrela C, Bammann LL, Estrela CRA, Silva RS, Pécora JD. Antimicrobial and chemical study of MTA, Portland cement, calcium hydroxide paste, Sealapex and Dycal. Braz Dent J. 2000; 11:19-27

5. Farsi N, Alamoudi N, Balto K, Mushayt A. Success of mineral trioxide aggregate in pulpotomized primary molars. J Clin Pediatric Dent. 2005; 29:307-12.

6. Barrieshi-Nusair KM, Qudeimat MA. A prospective clinical study of mineral trioxide aggregate for partial pulpotomy in cariously exposed permanent teeth. J Endod. 2006 ; 32:731-5.

7. Witherspoon DE, Small JC, Harris GZ. Mineral trioxide aggregate pulpotomies: a case series outcomes assessment. J Am Dent Assoc. 2006; 137:610-8.

8. Wucherpfenning AL, Green DB. Mineral trioxide vs Portland cement: two biocompatible filling materials. J Endod. 1999; 25:308.

9. Coomaraswamy KS, Lumley PJ, Hofmann MP. Effect of bismuth oxide radiopacifier content on the material properties of an endodontic Portland cement-based (MTA-like) system. J Endod. $2007 ; 33: 295-8$

10. Hwang YC, Lee SH, Hwang IN, Kang IC, Kim MS, Kim SH, Son HH, Oh WM. Chemical composition, radiopacity, \& biocompatibility of PC with bismuth oxide. Oral Surgery, Oral Medicine, Oral Pathology, Oral Radiology \& Endodontology 2009; 107(3):e96-e102.

11. Saidon J, He J, Zhu Q, Safavi K, Spangberg L. Cell and tissue reactions to mineral trioxide aggregate and Portland cement. Oral Surg Oral Med Oral Pathol Oral Radiol Endod. 2003; 95:483-9

12. Islam I, Chng HK, Yap AUJ. X-Ray diffraction analysis of MTA and Portland cement. J Endod. 2006; 39:220-5.

13. Dahl E, Cox CF. Healing of pulp exposures: an ultra structural study. J Oral Pathol Med 1991; 20:496 -501.

14. Holland R, de Souza V, Nery MJ, Faraco IM. Jr, Bernabé PF, Otoboni Filho JA, et al. Reaction of rat connective tissue to implanted dentin tube filled with mineral trioxide aggregate, Portland cement or calcium hydroxide. Braz Dent J. 2001; 12:3-8.

15. Holland R, Souza V, Murata SS, Nery MJ, Bernabé PF, Otoboni Filho JA, et al. Healing process of dog dental pulp after pulpotomy and pulp covering with mineral trioxide aggregate or Portland cement. Braz Dent J. 2001; 12:109-13.

16. Menezes R, Bramante CM, Letra A, Carvalho VGG, Garcia RB Histological evaluation of pulpotomies in dog using two types of mineral trioxide aggregate and white Portland cements as wound dressings. Oral Surg Oral Med Oral Pathol Oral Radiol Endod. 2004;98:376-9.

17. Min KS, Kim HI, Park HJ, Pi SH, Hong CU, Kim EC. Human pulp cells response to Portland cement in vitro. J Endod. 2007;33:163-6.

18. Dugal. M.Summary of: Pulpotomy of human primary molar with MTA and Portland Cement: a randomized controlled trial. British Dental Journal; 8/1/2009,vol.207 issue 3, p128

19. Barbosa AVH, The use of Portland cement in direct pulp capping: a systematic review. The Internet Journal of Dental Science. 2009; $7(2)$ :

20. Sampaio GC, Biocompatibility of PC as direct pulp capping material in human pulp, University of Parnambbuco, faculty of orthodontia, 2006.

21. De Deus G, Coutinho-Filho T. The use of white Portland cement as an apical plug in a tooth with a necrotic pulp and wide-open apex: a case report. Int Endod J. 2007; 40:653-60

22. Song JS, Mante FK, Romanow WJ, Kim S. Chemical analysis of powder and set forms of Portland cement, gray ProRoot MTA, white ProRoot MTA, and gray MTA-Angelus. Oral Surg Oral Med Oral Pathol Oral Radiol Endod. 2006; 102:809-15

23. De Deus G, Ximenes R, Gurgel-Filho ED, Plotkowski MC, Coutinho-Filho T. Cytotoxicity of MTA and Portland cement on human ECV 204 endothelial cells. Int Endod J. 2005; 38:604-9.

24. Spangberg LSW. Response to letter to the editor by Carolyn M. Prismus, PhD. Oral Surg Oral Med Oral Pathol Oral Radiol Endod. 2006;101:418. 
25. Soares IML, Pulpal Response to MTA- Compare to Calcium Hydroxide, $\mathrm{PhD}$ Thisis Faculty of Odontalgia de Aracatuba UNESP, 1999.

26. Pitt Fort TR, et.al. Using MTA as pulp-capping material. J. Am Dent Assoc. 1996; 27:1491-1494

27. Hungaro Duarte MA, de Oliveira EI Kadre GD. Radiopacity of PC associated with different radiopacifying agents. JE 2009; $35(5) ; 737-40$.

28. Duarte MAH, Demarchi ACCO, Yamashita JC, Kuga MC, Fraga SC. Arsenic release provided by MTA \& PC , Oral Surg Oral Medicine Oral Path Oral Radiol Endod.2005; 99:648-50 